\title{
SCIDOC
}

International Journal of Anatomy and Applied Physiology (IJAAP)

ISSN: 2572-7451

\section{Study on Fingertip Pattern in Bronchial Asthma Patients}

\author{
Research Article
}

Deepa TK ${ }^{1}$, Ursula Sampson ${ }^{2}$, Ranjith Sreedharan ${ }^{3 *}$

${ }^{1}$ Ph.D. Scholar, Meenakshi Academy of Higher Education and Research (MAHER) and Department of Anatomy, MES Medical College, Perinthalmanna, Kerala,679321, India.

${ }^{2}$ Department of Biochemistry, Meenakshi Medical College Hospital \& Research Institute, Kanchipuram, Tamil Nadu, 631552, India.

${ }^{3}$ Department of Anatomy, Jubilee Mission Medical College \& Research Institute, Thrissur, Kerala,680005, India.

\section{Abstract}

Background: Asthma is a complex, chronic inflammatory disorder of the airways of the lungs characterized by recurrent attacks of breathlessness, cough, and wheezing, which vary in its severity and frequency. Dermatoglyphics deals with the study of ridge patterns on the fingertips, palm, soles, and toes. Both asthma and dermatoglyphics are genetically determined and is influenced by genetic and environmental factors.

Objective: This study was done to compare the fingertip patterns in bronchial asthma patients with control group.

Methodology: Palm prints were obtained from both hands of 250 clinically diagnosed bronchial asthma patients who attended the OPDs of Respiratory medicine and Pediatrics of M E S Medical College, Perinthalmanna. Equal number of age and sex-matched controls without any respiratory or other systemic diseases were selected. The study included fingertip patterns like whorl, arch, loop, TFRC and AFRC.

Result: This study shows statistically significant difference between the fingertip patterns in bronchial asthma patients when compared with the control group.

Conclusion: Dermatoglyphic analysis of the fingertip pattern can serve as a non-invasive anatomical marker and a predictor tool to determine the individuals with bronchial asthma.

Keywords: Dermatoglyphics; Bronchial Asthma; Whorl; Arch; Loop.

\section{Introduction}

Dermatoglyphics is the study of patterns of dermal ridges in the palmar aspect of hands, digits and plantar aspect of foot and toes [1]. The fingerprints, once formed, are very resistant to later prenatal or postnatal influences, thus making it an ideal feature for genetic studies as well as for the identification of individuals. Epidermal ridges are formed between the 10th to 16th weeks of fetal development and, once formed remain permanent and never changes throughout the life, unless the skin is damaged to the depth of $1 \mathrm{~mm}$ [2]. Their frequencies vary considerably from one population to another. These include pattern frequencies on the palm, ridge counts on fingers, and differences between frequencies of patterns on the right and left fingers [3].
Asthma is a complex, chronic inflammatory disorder of airways of the lungs resulting in airflow obstruction, bronchial hyper responsiveness, wheeze, cough and breathlessness. It is one of the major public health problems. It has been estimated that more than 300 million people across the globe suffer from this disorder [4]. The increasing prevalence of asthma is associated with genetic changes and gene-environment interaction [5]. The association of dermatoglyphics and various diseases has opened new and vastly interesting diagnostic approaches. Dermatoglyphics can be used as a diagnostic aid for many diseases and for screening anomalies, which have a strong hereditary basis. Bronchial asthma is one of the most widely studied respiratory diseases, and its genetic influence has been well accepted [6]. As dermatoglyphic patterns and bronchial asthma are genetically determined, the present study

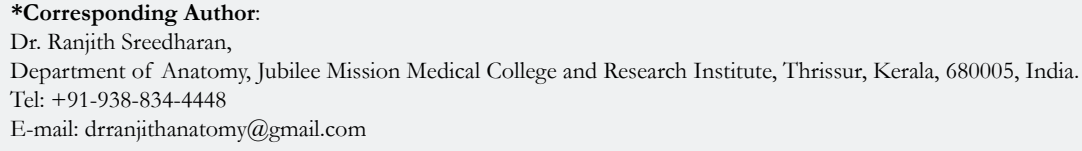

Received: November 05, 2020

Accepted: November 18, 2020

Published: November 19, 2020

Citation: Deepa TK, Ursula Sampson, Ranjith Sreedharan. Study on Fingertip Pattern in Bronchial Asthma Patients. Int J Anat Appl Physiol. 2020;6(4):156-159. doi: http://dx.doi.org/10.19070/2572-7451-2000029

Copyright: Ranjith Sreedharan ${ }^{\circ} 2020$. This is an open-access article distributed under the terms of the Creative Commons Attribution License, which permits unrestricted use, distribution and reproduction in any medium, provided the original author and source are credited. 
could help identify individuals with bronchial asthma.

\section{Materials and Methods}

A case-control study was performed in the department of Anatomy, MES Medical College, Perinthalmanna, Kerala. Study population includes 250 clinically diagnosed bronchial asthma patients, who attended the OPD's of Pediatric and Respiratory medicine departments of the same institution. An equal number of age and sex matched controls were selected. The ethical clearance was obtained from the Institutional Ethical Committee. The informed consent was taken from participants and parents in the case of children. The demographic data were collected from their medical records.

\section{Inclusion criteria}

- Clinically diagnosed case of bronchial asthma.

- All male and female bronchial asthma patients in the age group $6-60$ years.

- Subjects were residents of North Kerala

\section{Exclusion criteria}

- Subjects with known case of chromosomal abnormalities.

- Subjects who failed to deliver legible fingerprint pattern of one or both hands.

- Subjects in whose finger ridge were obscured by scars, deformities, birth defects and diseases on one or both hands.

- Any other systemic diseases

\section{Methodology}

The dermatoglyphic analysis was done using the Ink and paper method adopted from Cummin and Midlo [7]. Their fingerprints were taken from both hands of the case and controls. Before taking the prints, the subjects were asked to wash their hands with soap and water. After a few minutes, they were guided stepwise to provide a fingertip impression. A small paste of the ink was spread as a thin film on a glass sheet using a roller. With a relaxed arm their palm was placed on the inking sheet so that the entire palm was evenly covered with ink. The subjects were asked to keep their thumb with the ulnar edge downward and rolled toward the body. Other digits were placed with the radial edge downward and rolled away from the body. The fingerprints were taken onto the respective pre-labelled squares, one for each of the ten fingers. The fingerprints thus obtained were subjected to detailed dermatoglyphic analysis with the help of a magnifying hand lens. The fingertip patterns were then classified as per Galton's basic pattern - whorls, loops, and arches according to the number of triradii [8]. The qualitative parameters of the fingertip pattern, total finger ridge count (TFRC) and absolute finger ridge count (AFRC) were analyzed.

\section{Results}

Table 1 shows the percentage frequency of fingertip pattern of right and left hand. It shows that there was an increase in the number of whorls in almost all the digits in case subjects as compared to the control group. Further it was observed that in both thumbs whorl pattern were predominant followed by ulnar loop in cases, whereas in controls ulnar loop were predominant followed by whorls. In index and ring finger whorl pattern was frequent, followed by ulnar loop in both case and control subjects. The percentage of whorls was more in cases. In middle and little finger ulnar loop were predominant followed by whorls in both case and control subjects. In middle finger the percentage of ulnar loop is more in controls and in little finger it was more in cases. The arch pattern was less common and the radial loop was the least among the patterns in bronchial asthma patients compared to controls.

Table 2 presents the comparison of percentage frequency distribution of fingertip patterns of both hands with gender. In fingertip of thumb, whorl pattern was predominant in both sexes followed by ulnar loop in cases whereas in controls ulnar loop were predominant followed by whorls. In males, fingertip pattern of right index finger showed predominance of whorls in cases and ulnar loop in controls. The left middle finger of males showed more or less equal distribution of whorls and ulnar loop in cases whereas a predominance of ulnar loop was observed in controls. Table 3 shows the comparison of TFRC and AFRC in case and control and table 4 shows comparison of the same in both sexes. It was observed that the mean value of TFRC and AFRC were

Table 1. Percentage frequency of fingertip pattern of right and left hand in case and controls.

\begin{tabular}{|c|c|c|c|c|c|c|c|c|c|c|c|c|c|c|c|c|c|c|c|c|}
\hline \multirow{4}{*}{ FINGER } & \multicolumn{20}{|c|}{ RIGHT } \\
\hline & \multicolumn{4}{|c|}{ THUMB } & \multicolumn{4}{|c|}{ INDEX } & \multicolumn{4}{|c|}{ MIDDLE } & \multicolumn{4}{|c|}{ RING } & \multicolumn{4}{|c|}{ LITTILE } \\
\hline & \multicolumn{2}{|c|}{ CASE } & \multicolumn{2}{|c|}{ CONTROL } & \multicolumn{2}{|c|}{ CASE } & \multicolumn{2}{|c|}{ CONTROL } & \multicolumn{2}{|c|}{ CASE } & \multicolumn{2}{|c|}{ CONTROL } & \multicolumn{2}{|c|}{ CASE } & \multicolumn{2}{|c|}{ CONTROL } & \multicolumn{2}{|c|}{ CASE } & \multicolumn{2}{|c|}{ CONTROL } \\
\hline & $\mathbf{N}$ & $\%$ & $\mathbf{N}$ & $\%$ & $\mathbf{N}$ & $\%$ & $\mathbf{N}$ & $\%$ & $\mathbf{N}$ & $\%$ & $\mathbf{N}$ & $\%$ & $\mathbf{N}$ & $\%$ & $\mathbf{N}$ & $\%$ & $\mathbf{N}$ & $\%$ & $\mathbf{N}$ & $\%$ \\
\hline $\mathrm{A}$ & 10 & 4 & 8 & 3.2 & 19 & 7.6 & 25 & 10 & 26 & 10.4 & 20 & 8 & 0 & 0 & 17 & 6.8 & 0 & 0 & 10 & 4 \\
\hline $\mathrm{W}$ & 156 & 62.4 & 86 & 34.4 & 146 & 58.4 & 98 & 39.2 & 67 & 26.8 & 34 & 13.6 & 157 & 62.8 & 131 & 52.4 & 47 & 18.8 & 72 & 28.8 \\
\hline UL & 84 & 33.6 & 156 & 62.4 & 77 & 30.8 & 93 & 37.2 & 148 & 59.2 & 196 & 78.4 & 93 & 37.2 & 95 & 38 & 203 & 81.2 & 168 & 67.2 \\
\hline RL & 0 & 0 & 0 & 0 & 8 & 3.2 & 34 & 13.6 & 9 & 3.6 & 0 & 0 & 0 & 0 & 7 & 2.8 & 0 & 0 & 0 & 0 \\
\hline SIDE & \multicolumn{20}{|c|}{ LEFT } \\
\hline \multirow{3}{*}{ FINGER } & \multicolumn{4}{|c|}{ THUMB } & \multicolumn{4}{|c|}{ INDEX } & \multicolumn{4}{|c|}{ MIDDLE } & \multicolumn{4}{|c|}{ RING } & \multicolumn{4}{|c|}{ LITTILE } \\
\hline & \multicolumn{2}{|c|}{ CASE } & \multicolumn{2}{|c|}{ CONTROL } & \multicolumn{2}{|c|}{ CASE } & \multicolumn{2}{|c|}{ CONTROL } & \multicolumn{2}{|c|}{ CASE } & \multicolumn{2}{|c|}{ CONTROL } & \multicolumn{2}{|c|}{ CASE } & $\mathrm{CO}$ & TROL & $\mathrm{CA}$ & SE & $\mathrm{CON}$ & TROL \\
\hline & $\mathbf{N}$ & $\%$ & $\mathbf{N}$ & $\%$ & $\mathbf{N}$ & $\%$ & $\mathbf{N}$ & $\%$ & $\mathbf{N}$ & $\%$ & $\mathbf{N}$ & $\%$ & $\mathbf{N}$ & $\%$ & $\mathbf{N}$ & $\%$ & $\mathbf{N}$ & $\%$ & $\mathbf{N}$ & $\%$ \\
\hline $\mathrm{A}$ & 17 & 6.8 & 17 & 6.8 & 11 & 4.4 & 44 & 17.6 & 36 & 14.4 & 28 & 11.2 & 0 & 0 & 20 & 8 & 0 & 0 & 10 & 4 \\
\hline $\mathrm{W}$ & 147 & 58.8 & 80 & 32 & 122 & 48.8 & 99 & 39.6 & 97 & 38.8 & 75 & 30 & 160 & 64 & 144 & 57.6 & 64 & 25.6 & 64 & 25.6 \\
\hline $\mathrm{UL}$ & 86 & 34.4 & 153 & 61.2 & 52 & 20.8 & 93 & 37.2 & 108 & 43.2 & 147 & 58.8 & 90 & 36 & 86 & 34.4 & 186 & 74.4 & 176 & 70.4 \\
\hline RL & 0 & 0 & 0 & 0 & 65 & 26 & 14 & 5.6 & 9 & 3.6 & 0 & 0 & 0 & 0 & 0 & 0 & 0 & 0 & 0 & 0 \\
\hline
\end{tabular}


Table 2. Comparison of percentage frequency distribution of fingertip patterns in case and controls subjects of right and left hand with gender.

\begin{tabular}{|c|c|c|c|c|c|c|c|c|c|}
\hline \multirow{3}{*}{ FINGER } & \multirow{3}{*}{ PATTERN } & \multicolumn{4}{|c|}{ RIGHT } & \multicolumn{4}{|c|}{ LEFT } \\
\hline & & \multicolumn{2}{|c|}{ FEMALE } & \multicolumn{2}{|c|}{ MALE } & \multicolumn{2}{|c|}{ FEMALE } & \multicolumn{2}{|c|}{ MALE } \\
\hline & & Case \% & Control \% & Case $\%$ & Control \% & Case \% & Control \% & Case $\%$ & Control \% \\
\hline \multirow{3}{*}{ THUMB } & A & 5.22 & 3.60 & 2.59 & 2.70 & 6.72 & 7.91 & 6.90 & 5.41 \\
\hline & $\mathrm{W}$ & 53.73 & 34.53 & 72.41 & 34.23 & 56.72 & 35.25 & 61.21 & 27.93 \\
\hline & UL & 41.04 & 61.87 & 25.00 & 63.06 & 36.57 & 56.83 & 31.90 & 66.67 \\
\hline \multirow{4}{*}{ INDEX } & A & 8.96 & 10.79 & 6.03 & 9.01 & 5.22 & 21.58 & 3.45 & 12.61 \\
\hline & $\mathrm{W}$ & 56.72 & 41.73 & 60.34 & 36.04 & 48.51 & 43.17 & 49.14 & 35.14 \\
\hline & $\mathrm{UL}$ & 29.85 & 35.97 & 31.90 & 38.74 & 20.90 & 30.22 & 20.69 & 45.95 \\
\hline & $\mathrm{RL}$ & 4.48 & 11.51 & 1.72 & 16.22 & 25.37 & 5.04 & 26.72 & 6.31 \\
\hline \multirow{4}{*}{ MIDDLE } & $\mathrm{A}$ & 10.45 & 10.79 & 10.34 & 4.50 & 14.93 & 14.39 & 13.79 & 7.21 \\
\hline & $\mathrm{W}$ & 26.87 & 17.27 & 26.72 & 9.01 & 35.82 & 35.25 & 42.24 & 23.42 \\
\hline & $\mathrm{UL}$ & 58.21 & 71.94 & 60.34 & 86.49 & 44.78 & 50.36 & 41.38 & 69.37 \\
\hline & $\mathrm{RL}$ & 4.48 & 0.00 & 2.59 & 0.00 & 4.48 & 0.00 & 2.59 & 0.00 \\
\hline \multirow{4}{*}{ RING } & $\mathrm{A}$ & 0.00 & 7.91 & 0.00 & 5.41 & 0.00 & 10.79 & 0.00 & 4.50 \\
\hline & $\mathrm{W}$ & 60.45 & 53.96 & 65.52 & 50.45 & 60.45 & 58.27 & 68.10 & 56.76 \\
\hline & $\mathrm{UL}$ & 39.55 & 36.69 & 34.48 & 39.64 & 39.55 & 30.94 & 31.90 & 38.74 \\
\hline & RL & 0.00 & 1.44 & 0.00 & 4.50 & 0.00 & 0.00 & 0.00 & 0.00 \\
\hline \multirow{3}{*}{ LITTLE } & A & 0.00 & 5.76 & 0.00 & 1.80 & 0.00 & 5.76 & 0.00 & 1.80 \\
\hline & $\mathrm{W}$ & 18.66 & 32.37 & 18.97 & 24.32 & 22.39 & 30.22 & 29.31 & 19.82 \\
\hline & UL & 81.34 & 61.87 & 81.03 & 73.87 & 77.61 & 64.03 & 70.69 & 78.38 \\
\hline
\end{tabular}

Table 3. Comparison of TFRC \& AFRC in case and control subjects.

\begin{tabular}{|c|c|c|c|c|c|c|c|}
\hline & Case / control & $\mathbf{N}$ & Mean & Std. Deviation & Std. Error Mean & $T$ value & $P$-value \\
\hline \multirow{2}{*}{ TFRC } & Case & 250 & 128.54 & 37.045 & 2.343 & \multirow{2}{*}{3.35} & \multirow{2}{*}{$<0.001 * * *$} \\
\hline & Control & 250 & 117.88 & 34.05 & 2.153 & & \\
\hline \multirow{2}{*}{ AFRC } & Case & 250 & 186.09 & 73.851 & 4.671 & \multirow{2}{*}{3.991} & \multirow{2}{*}{$<0.001 * * *$} \\
\hline & Control & 250 & 160.52 & 69.374 & 4.388 & & \\
\hline
\end{tabular}

Level of significance $-\mathrm{P}<0.001^{* * *}, \mathrm{P}<0.01^{* *}, \mathrm{P}<0.05^{*}$ and not significant $\mathrm{NS}$,

Table 4. Comparison of TFRC and AFRC in case and control subjects with gender.

\begin{tabular}{|c|c|c|c|c|c|c|c|c|}
\hline Sex & & Case / control & $\mathbf{N}$ & Mean & Std. Deviation & Std. Error Mean & $T$ value & $\mathbf{P}$-value \\
\hline \multirow{4}{*}{ F } & \multirow{2}{*}{ TFRC } & Case & 134 & 127.59 & 39.864 & 3.444 & \multirow{2}{*}{2.684} & \multirow{2}{*}{$0.008^{* * *}$} \\
\hline & & Control & 139 & 115.16 & 36.643 & 3.108 & & \\
\hline & \multirow{2}{*}{ AFRC } & Case & 134 & 181.79 & 77.462 & 6.692 & \multirow{2}{*}{2.288} & \multirow{2}{*}{$0.023^{* *}$} \\
\hline & & Control & 139 & 160.78 & 74.271 & 6.3 & & \\
\hline \multirow{4}{*}{ M } & \multirow{2}{*}{ TFRC } & Case & 116 & 129.63 & 33.636 & 3.123 & \multirow{2}{*}{1.962} & \multirow{2}{*}{$0.051 \mathrm{NS}$} \\
\hline & & Control & 111 & 121.28 & 30.314 & 2.877 & & \\
\hline & \multirow{2}{*}{ AFRC } & Case & 116 & 191.06 & 69.447 & 6.448 & \multirow{2}{*}{3.502} & \multirow{2}{*}{$0.001^{* * *}$} \\
\hline & & Control & 111 & 160.19 & 63.037 & 5.983 & & \\
\hline
\end{tabular}

Level of significance $-\mathrm{P}<0.001^{* * *}, \mathrm{P}<0.01 * *, \mathrm{P}<0.05^{*}$ and not significant NS,

more in cases when compared with controls and the difference was statistically significant. When it was compared with gender these parameters were found to be statistically significant except in males the TFRC was statistically insignificant.

\section{Discussion}

Dermatoglyphics is presently being investigated to demonstrate not only unique individual differences, but also to give insight into group differences. It got the attention of medical researchers when it was found that many patients with chromosomal aberrations had unusual ridge formation. Human genetics and dermatoglyphic patterns together with clinical features are being employed for the diagnosis of many inherited diseases.

The current study shows the presence of whorls in thumb, index and ring fingers of bronchial asthma patients. An increased percentage of whorl patterns on both the thumbs in bronchial asthma patients were observed when compared with controls. This was well consistent with the findings of Sreenivasulu et al., [9] and 
Amrut et al., [10]. Sanjay et al., found that there was an increase in the number of whorls in almost all the digits in bronchial asthma patients and their first-degree relatives [11]. The middle finger of cases showed decreased frequency percentage of ulnar loop where as the little finger showed higher frequency percentage of ulnar loop. Abue et al. revealed the highest percentage frequency of whorls on the right thumb, followed by the ulnar loop on the little finger [12]. Bansal et al. found larger number of whorls in asthma patients than in the normal [13]. In this study, the percentage of arch was less in the index, ring, and little finger of bronchial asthma patients. Pakhale et al. ., [6] Hiru et al., [14], Shiva et al., [15], and Shahana et al., [16], also found a decrease in arch pattern in bronchial asthma patients. The current study shows increased frequency percentage of whorls on both sex,high percentage of whorl on right index and ring finger. Moreover percentage of ulnar loop is more in right little finger of female cases. Bansal et al. revealed that the group of normal males shows ulnar type of loops than the group with bronchial asthma which was statistically significant [13].

Amrut et al., found that the TFRC in bronchial asthma patients and their first-degree relatives shows no significance when compared with the control group [10]. We observed a higher value of TFRC in bronchial asthma patients when compared with controls. This coincides with the studies of Pakhale et al., [6] and Shahana et al., [16]. We noted that TFRC was found to be statistically significant in females but not in males.

AFRC in the present study shows a higher value in bronchial asthma case than the control. Male cases show a higher value than the female cases. The higher value of AFRC in bronchial asthma patient is coinciding with the studies of Pakhale et al., [6] and Sanjay Sahay et al., [11]. The present study shows an association between fingertip patterns in bronchial asthma patients when compared with controls.

\section{Conclusion}

Studies done in varied population have found significant correlation between different fingertip patterns and bronchial asthma. It can be used as a cost effective, non-invasive screening method for early identification of at-risk individuals with or without a family history of bronchial asthma. Although no single dermatoglyphic pattern can be used in making a diagnosis, several patterns, when combined, can be used to establish or to find a probable diagnosis.

\section{References}

[1]. Cummins H, Midlo C. Palmar and plantar epidermal ridge configurations (dermatoglyphics) in European-Americans. Am. J. Phys. Anthropol. 1926 Oct;9(4):471-502.

[2]. Adamu LH, Taura MG. Embryogenesis and applications of fingerprints-a review. Int. J. Hum. Anat. 2017 Jun 27;1(1):1.

[3]. Rife DC. Dermatoglyphics as Genetic Markers. InTrends in Dermatoglyphic Research 1990 (pp. 10-15). Springer, Dordrecht.

[4]. Bousquet J, Bousquet PJ, Godard P, Daures JP. The public health implications of asthma. Bull. World Health Organ. 2005;83:548-54.

[5]. Koppelman GH. Gene by environment interaction in asthma. Curr Allergy Asthma Rep. 2006 Mar 1;6(2):103-11.

[6]. Pakhale SV, Borole BS, Doshi MA, More VP. Study of the fingertip pattern as a tool for the identification of the dermatoglyphic trait in bronchial asthma. J Clin Diagn Res. 2012 Oct;6(8):1397-400.Pubmed PMID: 23205356.

[7]. Cummins H, Midlo C. Finger prints, palms and soles: an introduction to dermatoglyphics. New York: Dover Publications. 1961.

[8]. Galton F. Finger prints. Macmillan and Company. 1892.

[9]. Sreenivasulu K, Kumar PA, Nagaraju GC, Ravindranath G, Gaikwad MR. A study of palmar dermatoglyphics of bronchial asthma patients and their first degree relatives in Kurnool district. Indian J Allergy Asthma Immunol. 2012 Jan 1;26(1):2.

[10]. Mahajan AA, Gour KK, Thakare AE. The dermatoglyphic patterns in patients of bronchial asthma-a qualitative study. Int J Biol Med Res. 2011;2(3):806-07.

[11]. Sahay S, Giradkar UA, Chaudhari SH. A study of Dermatoglyphic Pattern and its Correlation in Bronchial asthma. IP Indian J Immunol Respir Med. 2018 May 15;3(2):82-6.

[12]. Andrew A, Duru F, Ibeabuchi NM, Bassey R. DIGITO-PALMAR DERMATOGLYPHIC PATTERNS OF ASTHMATICS IN LAGOS NIGERIA. Open Science Repository Anthropology. 2013 Aug 12(openaccess):e23050401.

[13]. Bansal IJ, BECTOR I. A comparative study of the finger dermatoglyphics of normal and asthmatic patients (male jat sikhs). Anthropologie. 1975 Jan 1:213-8.

[14]. Hiru N, Kumar P. Study of Dermatoglyphics in Children Age 5-18 Years with Bronchial Asthma. Indian J Public Health Res Dev. 2017;8(2):300-4.

[15]. Singh S, Khurana AK, Harode HA, Tripathi A, Pakhare A, Chaware P. Study of fingerprint patterns to evaluate the role of dermatoglyphics in early detection of bronchial asthma. J Nat Sci Biol Med. 2016 Jan-Jun;7(1):43-6. Pubmed PMID: 27003968.

[16]. Sahana BN, Bannur BM, Patil BG, Hadimani GA, Jose AP. Dermatoglyphic pattern in patients with bronchial asthma: A qualitative and quantitative study. Int J Healthc Biomed Res. 2013 Oct;2:38-42. 